\title{
PELATIHAN PEMANFAATAN GAS LPG SEBAGAI BAHAN BAKAR ALTERNATIF GENSET UNTUK MASYARAKAT NELAYAN
}

\section{A TRAINING ON THE UTILIZATION OF LPG AS ALTERNATIVE GAS FUEL FOR FISHERMEN}

\author{
Oleh: \\ Yovan Witanto, Hendra, Angky Puspawan \\ Program Studi Teknik Mesin, Fakultas Teknik Universitas Bengkulu \\ yovanmail@gmail.com
}

\begin{abstract}
This community service aimed at improving the knowledge and skills of the fishermen community of Pantai Jakat Bengkulu city in using gas fuel converted from liquid fuel. The community service was conducted in the form of a traning. The activities involved the fishermen in installing the converter kit of a gas fuel; trying out the genset which used the gas fuel; and evaluating the performance of the genset. After the training, the participant were asked to give opinion about the possibility of using the converted gas in their day to day fishing activities. The results of the training showed that the fishermen have a positive responses toward the use of the gas fuel for the genset. However, they still have some worries toward the safety of using the converted gas fuel.
\end{abstract}

Keywords: Genset, Gas Fuel

\section{PENDAHULUAN}

Generator set (genset) sangat dibutuhkan karena mampu mensuplai listrik ketika sumber listrik utama padam atau justru sebagai sumber suplai listrik utama jika tidak terdapat aliran listrik. Perkembangan genset kini semakin pesat dengan berbagai jenis model dengan variasi berbagai macam bahan bakar. Penggunaan genset ini menjadi terkendala manakala bahan bakar minyak semakin langka dan harga semakin melambung. Untuk itu perlu dipikirkan solusinya. Genset dengan bahan bakar gas mulai banyak dikembangkan, yang tentu saja lebih effisien (Witanto dan Budianto, 2015). Namun harga genset berbahan bakar gas tersebut relatif lebih tinggi dibandingkan yang berbahan bakar minyak. Untuk itu perlu dilakukan modifikasi agar genset berbahan bakar minyak bisa dipakai dengan menggunakan bahan bakar gas. Menurut Rosmayati (2012) genset berbahan bakar gas jauh lebih efektif dibandingkan yang berbahan bakar minyak. Seperti penelitian Romandoni dan Siregar (2013) yang menyebutkan bahwa bahan bakar LPG dapat meningkatkan torsi dan daya, sedangkan konsumsi bahan bakar mengalami penurunan.

Masyarakat di kawasan nelayan perikanan tangkap Pantai Zakat, didominasi oleh masyarakat nelayan. Rutinitas keseharian mereka adalah mencari ikan di tengah laut. 
Aktivitas mencari ikan tersebut tentu saja memerlukan bantuan energi listrik. Baik digunakan untuk penerangan maupun untuk keperluan penunjang, seperti mesin pendingin dan mesin pemanas air. Disamping itu penerangan dari genset ini menurut ketua nelayan Pantai Zakat juga berguna untuk menarik perhatian ikan-ikan yang ada di dasar laut untuk mendekat. Kebutuhan pasokan listrik ini tentu saja belum tercukupi jika mengandalkan sumber listrik dari mesin kapal. Untuk itu diperlukan genset. Genset ini tidak hanya diperlukan untuk kebutuhan penerangan di laut, tapi saat di darat pun, para nelayan ini masih perlu penerangan. Biasanya setelah sampai di darat para nelayan langsung mempersiapkan hasil tangkapan mereka untuk dijual. Penerangan listrik PLN di area lokasi pemukiman nelayan masih kurang memadai (Prasetya et al., 2013). Dengan demikian genset ini sangat membantu kehidupan ekonomi masyarakat nelayan di pesisir Kota Bengkulu bisa dibilang masih di taraf menengah ke bawah. Kebutuhan penggunaan bahan bakar minyak sebagai sumber energi genset dirasakan masih terlalu mahal. Setiap hari mereka berlayar, diperlukan sekitar lima liter bahan bakar minyak untuk kebutuhan bahan bakar genset.

Kebutuhan bahan bakar minyak untuk keperluan mesin kapal juga tidak sedikit. Untuk itu perlu dicoba menggunakan alternatif bahan bakar lain, yakni gas LPG (Milda, 2012). Masyarakat di pesisir pantai Kota Bengkulu tersebut perlu dilatih bagaimana cara memodifikasi agar genset berbahan bakar minyak, dapat juga dioperasikan dengan bahan bakar gas LPG, yang tentu saja lebih ekonomis. Kegiatan pengabdian ini akan lebih fokus ke mesin genset nelayan terlebih dahulu. Untuk meyakinkan nelayan bahwa penggunaan genset berbahan bakar gas lebih baik kinerjanya dan lebih hemat dibanding berbahan bakar minyak, maka pada kegiatan ini akan disampaikan juga teknik untuk uji unjuk kerja genset melalui kegiatan pelatihan. Kegiatan pengabdian ini bertujuan untuk meningkatkan pengetahuan dan kemampuan masyarakat nelayan dalam konversi penggunaan bahan bakar cair ke bahan bakar gas. Kegiatan ini diharapkan mendatangkan manfaat kepada nelayan Pantai Zakat Kota Bengkulu dalam rangka penghematan penggunaan bahan bakar minyak, sehingga perekonomian bisa meningkat.

\section{METODE PENGABDIAN}

Mitra yang akan diajak kerjasama dalam kegiatan ini adalah para nelayan perikanan tangkap Pantai Zakat, Kota Bengkulu. Pemilihan mitra tersebut karena penggunaan genset para nelayan untuk proses penangkapan ikan tergolong cukup tinggi. Jadi sangat cocok untuk diajak kerja sama. Pelatihan pemanfaatan gas LPG sebagai bahan bakar genset dilakukan dengan melibatkan mahasiswa Program Studi Teknik Mesin yang sedang meneliti tentang uji unjuk kerja genset berbahan bakar gas LPG. Kaji tindak penggunaan bahan bakar gas LPG dilakukan dengan melakukan ujicoba gas LPG pada genset berbahan bakar minyak yang telah dimodifikasi dengan bantuan konverter kit. Bahan dan alat yang 
digunakan untuk memodifikasi tersebut terdiri dari regulator LPG, tabung gas LPG $3 \mathrm{~kg}$, membran, valve, selang dan mesin geset, seperti terlihat pada gambar 1.

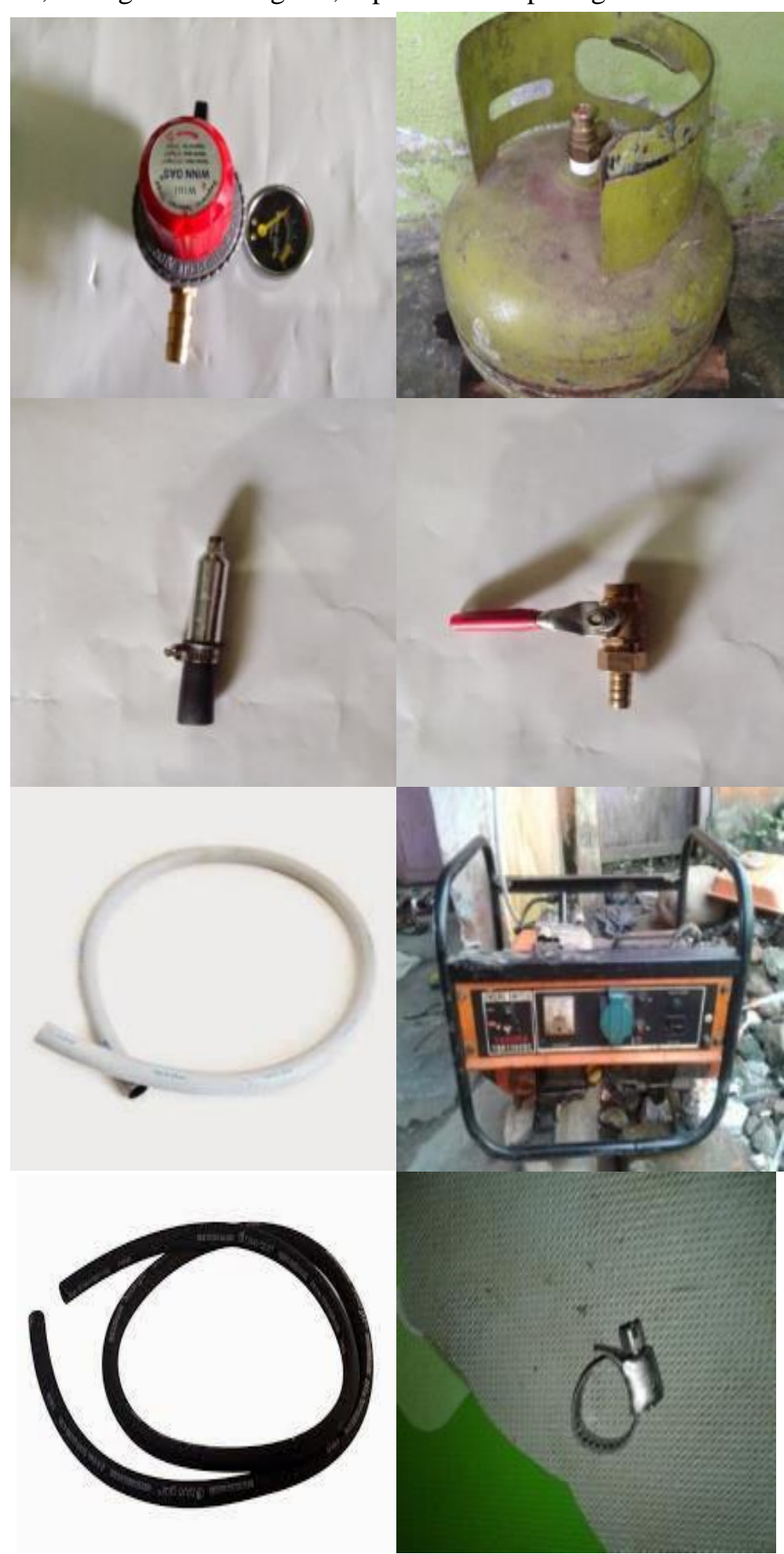

Gambar 1. Converter kit untuk modifikasi genset agar dapat digunakan bahan bakar gas 
Selanjutnya peralatan tersebut dirangkaikan seperti terlihat pada gambar 2.

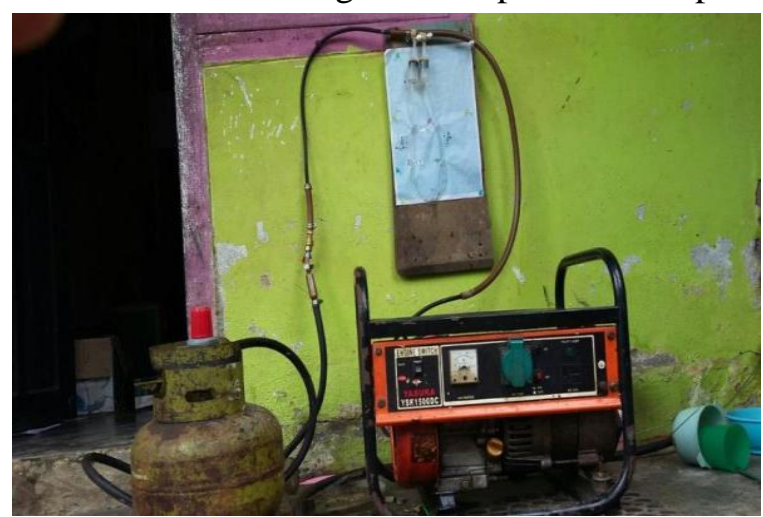

Gambar 2. Instalasi modifikasi genset berbahan bakar gas LPG

Uji unjuk kerja pertama dilakukan dengan mengoperasikan genset dengan bahan bakar cair (premium). Genset diberi beban pada putaran tertentu. Uji coba kedua yakni diulang dengan perlakuan yang sama, namun bahan bakar cair diganti dengan bahan bakar gas LPG. Selanjutnya hasil uji unjuk kerja tersebut dibandingkan. Peserta dilibatkan dalam merangkai peralatan modifikasi bahan bakar gas dan selanjutnya diminta menilai unjuk kerja mesin genset serta kebutuhan bahan bakar yang diperlukan selama pengujian. Selanjutnya masyarakat akan diminta pendapat tentang keberlanjutan dari kegiatan ini dan kemungkinan untuk menerapkannya pada operasional genset untuk keperluan mencari ikan. Masyarakat yang berminat untuk mencoba akan dipandu dalam pemasangan instalasi dan didampingi mahasiswa yang sedang skripsi di bidang tersebut.

\section{HASIL DAN PEMBAHASAN}

Kegiatan pengabdian ini dilaksanakan di Pantai Zakat, Kota Bengkulu. Awal kegiatan yaitu diadakan pertemuan dan dialog dengan masyarakat nelayan tentang kemunginan penggunaan bahan bakar gas (LPG) sebagai alternatif bahan bakar genset. Pertemuan penjajagan dilakukan di beberapa lokasi perkumpulan nelayan di sekitar Pantai Zakat Kota bengkulu, seperti terlihat pada gambar3.

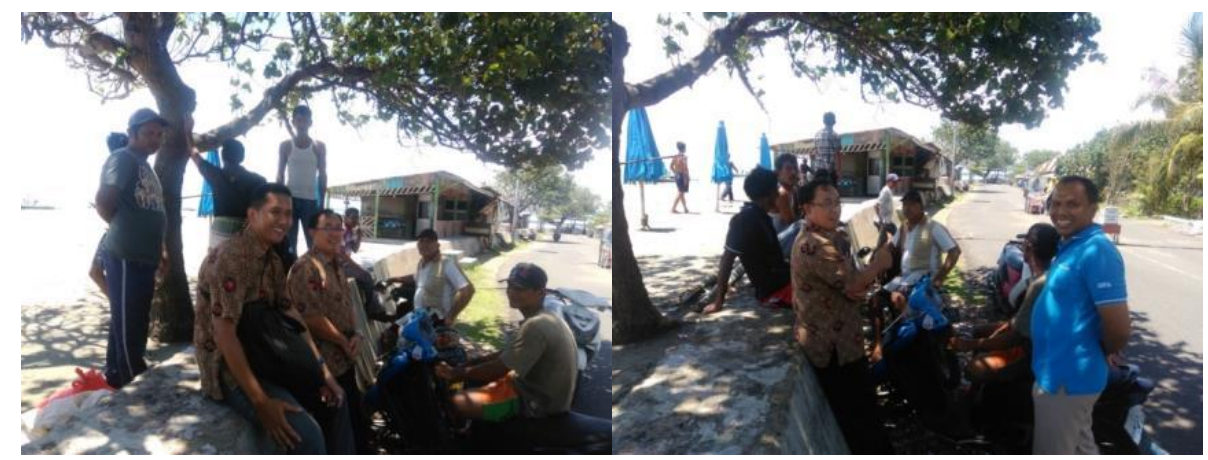

Gambar 3. Pertemuan penjajagan awal dengan masyarakat Pantai Zakat, Kota Bengkulu 
Hasil kegiatan penjajagan tersebut disepakati bahwa masyarakat nelayan Pantai Zakat bersedia untuk berpartisipasi dalam kegiatan sosialisasi ini. Kegiatan diawali dengan pendataan peserta yang akan dilakukan oleh ketua perkumpulan nelayan Pantai Zakat Kota Bengkulu, yang bernama Buyung. Dari pendataan tersebut berhasil didapat sekitar 20 peserta yang bersedia mengikuti kegiatan sosialisasi tersebut.

Peserta dikumpulkan di lokasi yang telah ditentukan oleh ketua masyarakat nelayan, kemudian diberikan pengarahan. Pemberian materi diawali dengan penjelasan komponen gas LPG, kemudian dilanjutkan dengan pengenalan cara kerja mesin genset, dan pengenalan cara menghitung unjuk kerja mesin genset. Hal ini perlu disampaikan agar masyarakatat mengetahui perbandingan saat menggunakan genset berbahan bakar cair dengan genset yang berbahan bakar gas. Kegiatan selanjutnya adalah pengenalan cara menghitung kebutuhan bahan bakar. Hal ini bertujuan agar masyarakat mengetahui bagaimana perbandingan penggunaan bahan bakar cair dengan bahan bakar gas. Kegiatan kemudian dilajutkan dengan pelatihan pengenalan alat yang akan digunakan untuk memodifikasi karburator genset berbahan bakar cair, agar bisa dipakai dengan menggunakan bahan bakar gas LPG.

Kegiatan kemudian dilanjutkan dengan evaluasi terhadap kegiatan pelatihan awal. Dari hasil pelatihan awal tersebut terlihat peserta sudah mampu memahami bagaimana cara instalasi peralatan converter kit untuk memodifikasi genset agar dapat digunakan bahan bakar gas. Selanjutnya pelatihan dilanjutkan pada minggu berikutnya yakni pelaksanaan uji coba alat, seperti terlihat pada gambar 4.

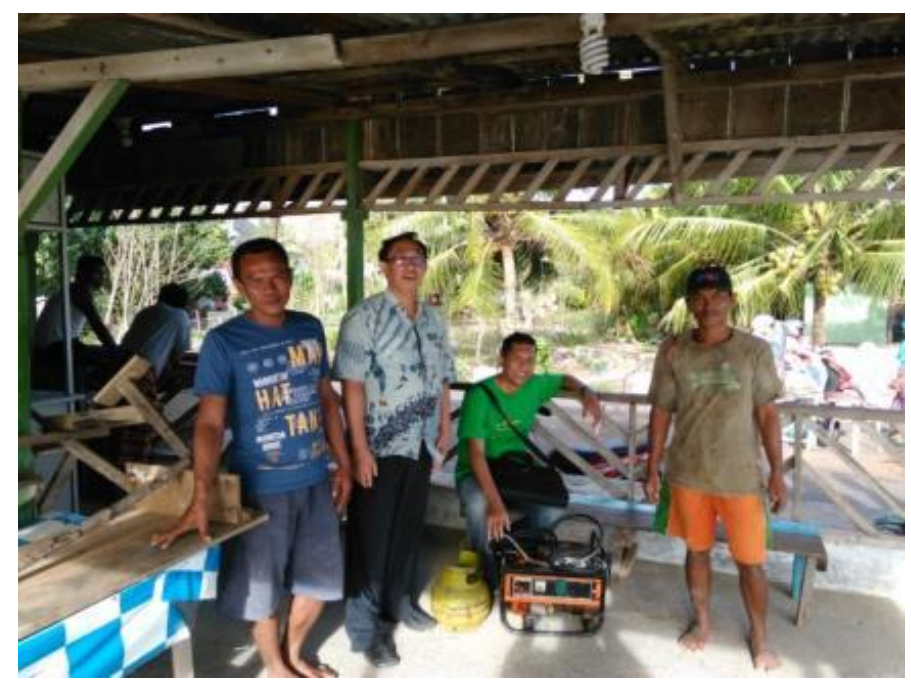



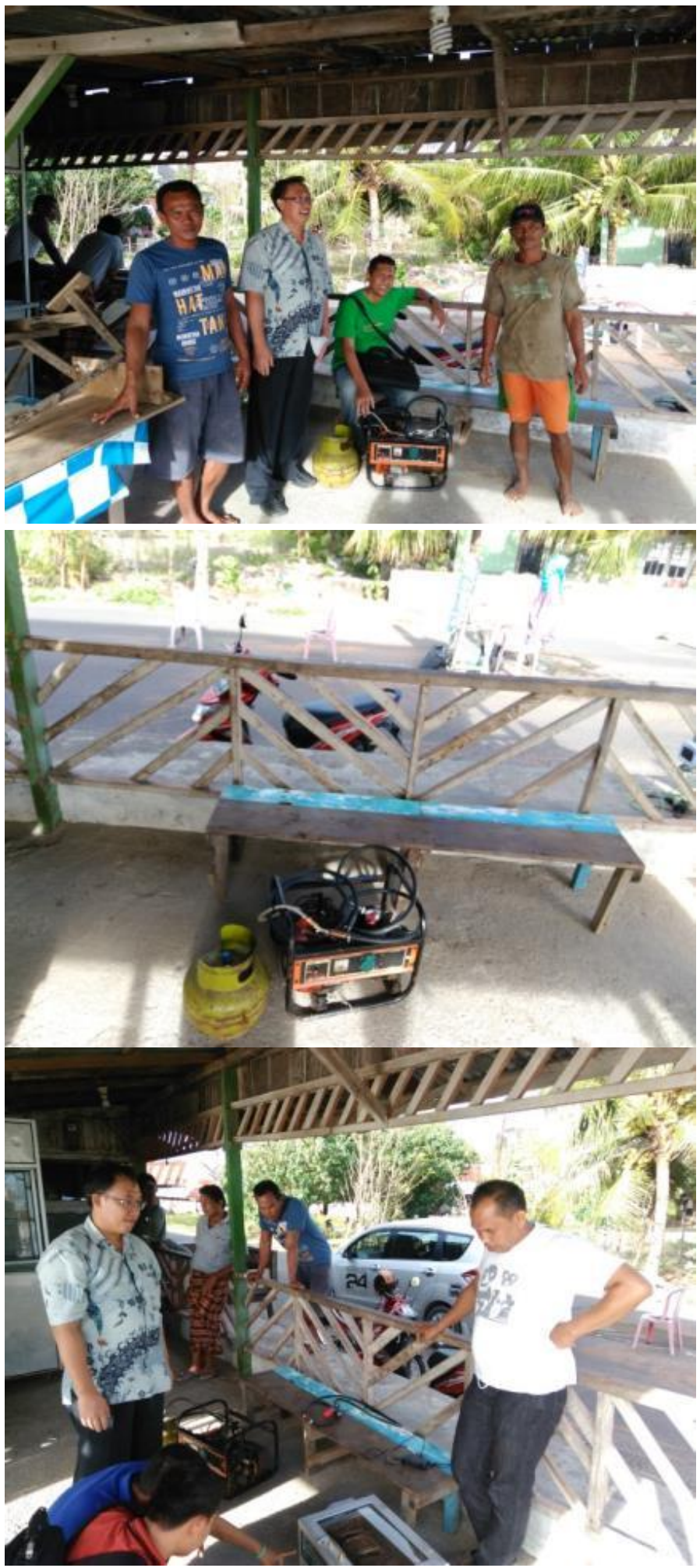


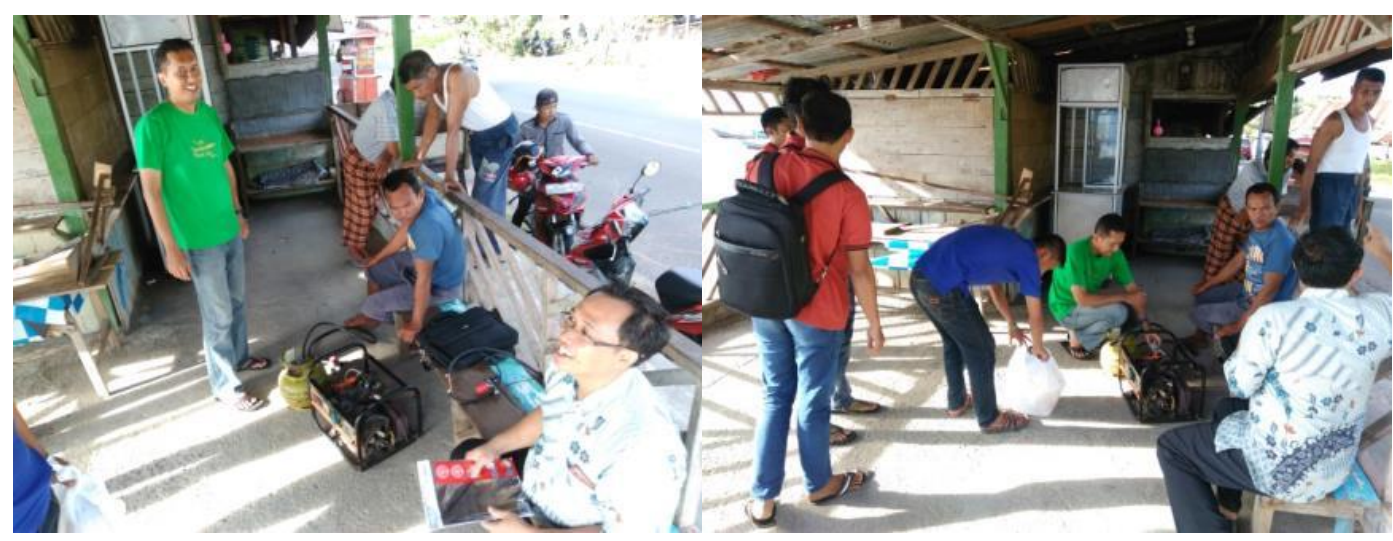

Gambar 4. Pelaksanaan uji coba genset berbahan bakar gas LPG rakitaN

Dari hasil uji coba peralatan tersebut, terlihat bahwa penggunaan bahan bakar gas sebagai alternatif pengganti bahan bakar cair untuk genset, sebagai penunjang keperluan kegiatan penangkapan ikan oleh masyarakat nelayan di Pantai Zakat cukup menarik. Peserta pelatihan dengan antusias mencoba secara bergantian. Namun yang menjadi kendala terbesar dalam kegiatan sosialisasi ini adalah sebagian masyarakat masih takut dengan menggunakan bahan bakar gas. Hal ini disebabkan minimnya informasi yang mereka dapat, bahwa bahan bakar gas, seperti LPG itu aman.

Penutup dari kegiatan ini yakni dilakukan evaluasi. Dari hasil evaluasi dapat diketahui bahwa pemahaman masyarakat nelayan bisa dikategorikan bagus. Bahkan beberapa nelayan menginginkan pelatihan lebih lanjut, agar pemanfaatan bahan bakar gas ini juga bisa diaplikasikan pada motor bakar kapal mereka, baik yang menggunakan bahan bakar solar maupun bahan bakar bensin. Masyarakat nelayan sepakat jika diadakan kegiatan pengabdian lanjutan tentang hal tersebut setelah kegiatan pengabdian ini selesai.

\section{KESIMPULAN DAN SARAN}

Hasil kegiatan pengabdian pada masyarakat nelayan ini berhasil mempromosikan tentang bahan bakar gas sebagai alternatif pengganti bahan bakar cair untuk keperluan bahan bakar genset untuk menunjang kegiatan nelayan di Pantai Zakat Kota Bengkulu dalam mencari ikan di malam hari. Namun kegiatan ini sedikit terkendala. Hal ini disebabkan beberapa nelayan masih merasa khawatir dan takut akan penggunaan bahan bakar gas LPG. Mereka khawatir penggunaan bahan bakar gas LPG kurang aman dan takut meledak. Hal ini bisa dipahami karena sosialisasi tentang keamanan penggunaan LPG masih minim. Hasil kegiatan pengabdian ini juga didapatkan peluang untuk pengabdian lanjutan. Masyarakat nelayan sangat tertarik tentang penggunaan bahan bakar gas LPG untuk keperluan bahan bakar motor kapal mereka, baik yang bermesin diesel maupun bermesin bensin 4 langkah. Untuk itu akan dilaksanakan kegiatan pengabdian masyarakat lanjutan. 


\section{DAFTAR PUSTAKA}

Milda, F., 2012, Pemanfaatan LPG Sebagai Bahan Bakar Sepeda Motor dan Karakteristik Minyak Lumasnya, Lembaran Publikasi Minyak dan Gas Bumi, Vol. 46 No.1, 35-42 https://www.google.co.id/url?sa=t\&rct=j\&q=\&esrc=s\&source=web\&cd=1\&cad=rja \&uact=8\&ved=0ahUKEwiJtJWxysHLAhVF6aYKHRTsCLgQFggaMAA\&url=http $\% 3 \mathrm{~A} \% 2 \mathrm{~F} \% 2 \mathrm{~F} 202.46 .252 .13 \%$ 2Fojslemigas\%2Findex.php\%2FLPMGB\%2Farticle \%2Fview\%2F63\%2F63\&usg=AFQjCNHpRsRBvhOqe2xg8w9xw41KY3OFxA\&bv $\mathrm{m}=$ bv.116636494,d.dGY diakses diakses tanggal 15-03-2015.

Prastya, R., Susilo, B., Lutfi, M., 2013, Pengaruh Penggunaan Bahan Bakar Biogas terhadap Emisi Gas Buang Mesin Generator Set, Jurnal Keteknikan Pertanian Tropis dan Biosistem Vol. 1 No. 2, Juni 2013, 77-84, Malang.

Romandoni, N., dan Siregar, I.H., 2013, Studi Komparasi Performa Mesin Dan Kadar Emisi Gas Buang Sepeda Motor Empat Langkah Berbahan Bakar Bensin Dan Lpg, Jurnal Teknik Mesin, Vol 1, No 2, http://ejournal.unesa.ac.id/index.php/jtmunesa/article/view/603/baca-artikel diakses tanggal 15-03-2016.

Rosmayati L., 2012, Kajian Komposisi Hidrokarbon dan Sifat Fisika-Kimia LPG untuk Rumah Tangga, Lembaran Publikasi Minyak Dan Gas Bumi, Vol. 46 No. 2, Agustus 2012, 69-77, http://202.46.252.13/ojslemigas/index.php/LPMGB/article/view/67/67 diakses tanggal 15-03-2015.

Witanto Y., dan Budiyanto, 2015, Analisis Pengaruh Penggunaan Biodiesel Dari Pome Sebagai Alternatif Energi Baru Terbarukan (Ebt) Terhadap Unjuk Kerja Mesin Genset Diesel Prosiding, Seminar Nasional Sains \& Teknologi VI Lembaga Penelitian dan Pengabdian Universitas Lampung. 